Tropical Journal of Pharmaceutical Research October 2013; 12 (5): 685-690

ISSN: $1596-5996$ (print); 1596-9827 (electronic)

(C) Pharmacotherapy Group, Faculty of Pharmacy, University of Benin, Benin City, 300001 Nigeria.

All rights reserved.

Available online at http://www.tjpr.org

Original Research Article

http://dx.doi.org/10.4314/tjpr.v12i5.4

\title{
Effect of Sucrose Esters on the Physicochemical Properties of Wheat Starch
}

\author{
Jie Zeng*, Haiyan Gao and GuangLei Li \\ School of Food Science, Henan Institute of Science and Technology, Xinxiang, 453003, China \\ *For correspondence: Email: zengjie623@163.com
}

Received: 21 September 2012

Revised accepted: 5 June 2013

\begin{abstract}
Purpose: To investigate the effect of sucrose esters on the physicochemical properties of wheat starch. Methods: Sucrose ester was mixed with wheat starch extracted from normal soft wheat cultivars and heated. Change in starch properties arising from the interaction between were assessed for starch blue value, viscosity, solubility and retrogradation. In addition, the structure and thermodynamic properties of the modified starch were analyzed by Fourier transform infrared spectroscopy (FITR), scanning electron microscopy (SEM) and differential scanning calorimetry (DSC).

Results: The properties of wheat starch changed greatly by adding different sucrose esters to their structures. Starch containing $0.30 \%$ sucrose esters had the lowest peak (2034 cps), trough (1331 cps), final (1896 cps), setback viscosities (565 cps), iodine value (0.378), supernatant volume (76.6mL), and lower dissolution rate (0.063g). The unmodified starch had higher peak (3576 cps), trough (2971 cps), final (4394 cps), setback viscosities (1423 cps), blue value (0.464), supernatant volume (85.4 $\mathrm{mL}$ ), and dissolution rate ( $0.076 \mathrm{~g}$ ). After adding sucrose esters, the onset temperature (To) and peak temperature (Tp) of wheat starches increased by $1-5{ }^{\circ} \mathrm{C}$ and $1-3{ }^{\circ} \mathrm{C}$, respectively; the conclusion temperature (TC) and enthalpy, however, decreased by $5-6^{\circ} \mathrm{C}$ and $0.2-1.9 \mathrm{~J} / \mathrm{g}$, respectively. SEM and FT-IR showed that the microstructure and molecular structure of the starches with sucrose esters did not differ significantly from that of the unmodified starch.

Conclusion: Incorporation of small amounts of sucrose ester in the structure of wheat starch can change the physicochemical properties of the starch to meet various functional requirements, including in the food and pharmaceutical industries.
\end{abstract}

Keywords: Sucrose esters, Wheat starch, Viscosity, Microscopy; Microstructure, Differential scanning calorimetry, Fourier transform infrared spectroscopy.

Tropical Journal of Pharmaceutical Research is indexed by Science Citation Index (SciSearch), Scopus, International Pharmaceutical Abstract, Chemical Abstracts, Embase, Index Copernicus, EBSCO, African Index Medicus, JournalSeek, Journal Citation Reports/Science Edition, Directory of Open Access Journals (DOAJ), African Journal Online, Bioline International, Open-J-Gate and Pharmacy Abstracts

\section{INTRODUCTION}

Several studies have reported structural and functional differences between wheat starches [1-4]. Starches from wheat have a bimodal granule size distribution, that is, $A$ and $B$ granules. A and $B$ granules differ in structure and functionality, and significant correlations were found between a number of these characteristics of the isolated A and B granules [5-8].
Emulsifiers are usually added to cereal flours in order to produce specific desired characteristics such as soft structure [9]. Emulsifiers show both hydrophilic and hydrophobic properties on the same molecule. The lipophilic portions of emulsifiers are believed to form a complex with the amylose fraction of starch during cooking, retarding starch gelatinization and decreasing swelling [10]. Complexation with lipids reduces 
the solubility of starch in water, alters the rheological properties of pastes, decreases swelling capacity, increases gelatinization temperature and reduces gel rigidity [11-15].

The objective of this paper was to investigate the effect of incorporation of sucrose esters on the properties of wheat starch, determine the optimal concentration of sucrose esters and provide some theoretical basis for modification of wheat starches.

\section{EXPERIMENTAL}

\section{Materials}

Normal soft wheat cultivars, obtained from the Henan Institute of Science and Technology, was the source of starches for the study. Sucrose fatty acid ester was purchased from Hangzhou Jinhelai Food Additive Co Ltd. Sodium hydroxide, ethanol, acetic acid, iodine, potassium iodide were of analytical grade.

\section{Isolation of starch}

The wheat starch was isolated following the method reported by Kasemsuwan et al [15]. The isolated starch was washed with water and ethanol, and recovered by filtration using filter paper before drying in a convection oven at 32 ${ }^{\circ} \mathrm{C}$ for $48 \mathrm{~h}$.

\section{Pasting properties}

Pasting properties of the starch were determined by using a Rapid Visco-Analyzer (RVA-Series 4, Newport Scientific Pty. Ltd., Warriewood, Australia). Each starch suspension (8\%, w/w; 28 $\mathrm{g}$ total weight) was equilibrated at $50{ }^{\circ} \mathrm{C}$ for $1 \mathrm{~min}$ and then heated at a rate of $6{ }^{\circ} \mathrm{C} / \mathrm{min}$ to $95{ }^{\circ} \mathrm{C}$ and then maintained at that temperature for 5 min. The sample was then cooled to $50{ }^{\circ} \mathrm{C}$ at a rate of $6{ }^{\circ} \mathrm{C} / \mathrm{min}$. A rotating speed of the paddle (160 rpm) was used except the paddle speed was $960 \mathrm{rpm}$ at the first $10 \mathrm{~s}$.

\section{Thermal properties}

Thermal properties of the starches were analyzed using a differential scanning calorimeter (DSC, TA instruments Waters LLC, New Castle, DE, USA) equipped with a thermal analysis data station. Aluminum pans (PerkinElmer) were used for the analysis. Starch samples (2 mg, dried starch basis) were precisely weighed in the sample pans, mixed with distilled water $(4 \mathrm{ml})$, and sealed. The heating rate was at $10{ }^{\circ} \mathrm{C}$ per min over the temperature range of $20-150{ }^{\circ} \mathrm{C}$. Indium and zinc were used as the reference standards.

Enthalpy change $(\Delta \mathrm{H})$, gelatinization onset

temperature (To), peak temperature (Tp), and conclusion temperature (Tc) were measured. The data were averages of a minimum of three replicates of each starch sample.

\section{Blue value}

The blue value (BV) was determined in triplicate according to the method of Klucinec and Thompson with some modifications [16]. The sample $(0.10 \mathrm{~g})$ was thoroughly wetted with $1 \mathrm{ml}$ of absolute ethyl alcohol and $9 \mathrm{~mL}$ of $1 \mathrm{~mol} / \mathrm{l}$ sodium hydroxide added. Then sample was dispersed in boiling water for $10 \mathrm{~min}$ and cooled rapidly. Starch dispersion $(5 \mathrm{ml})$ was taken in a $100 \mathrm{~mL}$ volumetric flask along with $50 \mathrm{~mL}$ of deionized water, $1 \mathrm{~mol} / \mathrm{L}$ acetic acid solution $1 \mathrm{~mL}$ and iodine reagent $1 \mathrm{~mL}\left(\mathrm{I}_{2}-\mathrm{KI}\right.$ solution, $2.0 \mathrm{mg}$ $\mathrm{I}_{2} / \mathrm{mL}$ and $20.0 \mathrm{mg} \mathrm{KI} / \mathrm{mL}$ ). The volume was made up to $100 \mathrm{~mL}$ with distilled water and mixed immediately. Then standing $10 \mathrm{~min}$ and colored. Control solutions were made in the same way but without sample. All samples were scanned from 500 to $800 \mathrm{~nm}$ with an Ultraspec III UV-visible spectrophotometer (Amersham Pharmacia Biotech, Uppsala, Sweden). The BV was the extinction at $620 \mathrm{~nm}$ under the above experimental conditions. The $\mathrm{k}_{\max }$ was the wavelength (in $\mathrm{nm}$ ) at which the extinction was the highest over the range of the wavelengths.

\section{Dissolution rate}

$50 \mathrm{~mL}$ mass fraction of $2 \%$ starch was stirred at $80{ }^{\circ} \mathrm{C}$ for $30 \mathrm{~min}$, then centrifuged at $3000 \mathrm{r} / \mathrm{min}$ for 20min. and the supernatant was poured into a dried evaporating dish, and then moved into the oven and dried to a constant weight at $105{ }^{\circ} \mathrm{C}$, tThe weight of dissolved starch was obtained (A), where $\mathrm{m}$ was the sample weight. Dissolution rate of starch samples (S) was determined as in Eq 1. $\mathrm{S}(\%)=(\mathrm{A} / \mathrm{m}) 100$

\section{Retrogradation volume}

A starch paste (1\%) was prepared with boiled water and heated in a water for $30 \mathrm{~min}$ and cooled at room temperature (about $25^{\circ} \mathrm{C}$ ). It was transfered into a $100 \mathrm{~mL}$ graduated cylinder. Starch retrogradation volume (supernatant volume) was observed after standing for $10 \mathrm{~h}$.

Scanning electron microscopy (SEM). SEM micrographs were recorded with a Quanta 200 environmental scanning electron microscope 
(FEl Company, Hillsboro, Oregon, USA). The samples were evenly distributed on SEM specimen stubs with double adhesive tape. The micrographs were obtained with an accelerating potential of $15 \mathrm{kV}$ under low vacuum. The micrographs obtained were used to detect any changes to the starch granules [17].

\section{Fourier transform infrared spectroscopy}

In order to further determine the structure of the wheat starches, FT-IR spectra were obtained using FT-IR (Nicolet 470; Perkin Elmer Inc., Waltham, MA, USA). The spectra were recorded in transmission mode from 4,000 to $500 \mathrm{~cm}^{-1}$ (mid-infrared region) at a resolution of $0.44 \mathrm{~cm}^{-1}$. The sample was diluted with $\operatorname{KBr}(1: 100$, w/w) before acquisition and the background value from pure $\mathrm{KBr}$ was acquired before the sample was scanned.

\section{Dara analysis}

Statistical analysis was carried out using DPS 7.05 software (Zhejiang University, Hangzhou, China). All measurements were repeated three times, and mean values used as data. Statistical comparisons were carried out using Dixon test. $P$-values of $<0.05$ or $<0.01$ were considered significant.

\section{RESULTS}

\section{Viscosity}

Table 1 summarizes the characteristics of the modified starches while Fig 1 shows their RVA viscograms. Peak, trough, final and setback of all the samples treated with sucrose ester decreased while breakdown and pasting temperature increased a little compared with the control (ck). The starch with $0.30 \%$ sucrose esters had peak (2034 cps), trough (1331 cps), final (1896 cps), setback viscosities (565 cP), blue value $(0.378)$ than other samples. Starch with $0.20 \%$ sucrose esters had lowest breakdown viscosities.

Table 1: Rapid visco-analyzer parameters for wheat starch modified with sucrose esters

\begin{tabular}{lccccccc}
\hline $\begin{array}{l}\text { Content of sucrose } \\
\text { esters }(\%)\end{array}$ & $\begin{array}{c}\text { Peak } \\
\text { (cP) }\end{array}$ & $\begin{array}{c}\text { Trough } \\
\text { (cP) }\end{array}$ & $\begin{array}{c}\text { Breakdown } \\
\text { (cP) }\end{array}$ & $\begin{array}{c}\text { Final } \\
\text { (cP) }\end{array}$ & $\begin{array}{c}\text { Setback } \\
\text { (cP) }\end{array}$ & $\begin{array}{c}\text { Peak } \\
\text { time } \\
(\mathbf{m i n})\end{array}$ & $\begin{array}{c}\text { Pasting } \\
\text { temp } \\
\left({ }^{\circ} \mathbf{C}\right)\end{array}$ \\
\hline $\mathrm{ck}$ & $3576^{*}$ & $2971^{*}$ & 605 & 4394 & 1423 & 6.8 & 86.75 \\
0.10 & 2562 & 1778 & 784 & 3037 & 1259 & 7 & 89.05 \\
0.20 & 2315 & 1642 & 673 & 2684 & 1042 & 7 & 89.15 \\
0.30 & 2034 & 1331 & 703 & 1896 & $565^{*}$ & 6.4 & 88.3 \\
0.40 & 2238 & 1415 & 823 & 2779 & 1364 & 7 & 88.2 \\
0.50 & 2568 & 1461 & $1107^{*}$ & 3103 & 1642 & 7 & 87.5 \\
\hline
\end{tabular}

* Significant at $p<0.05$

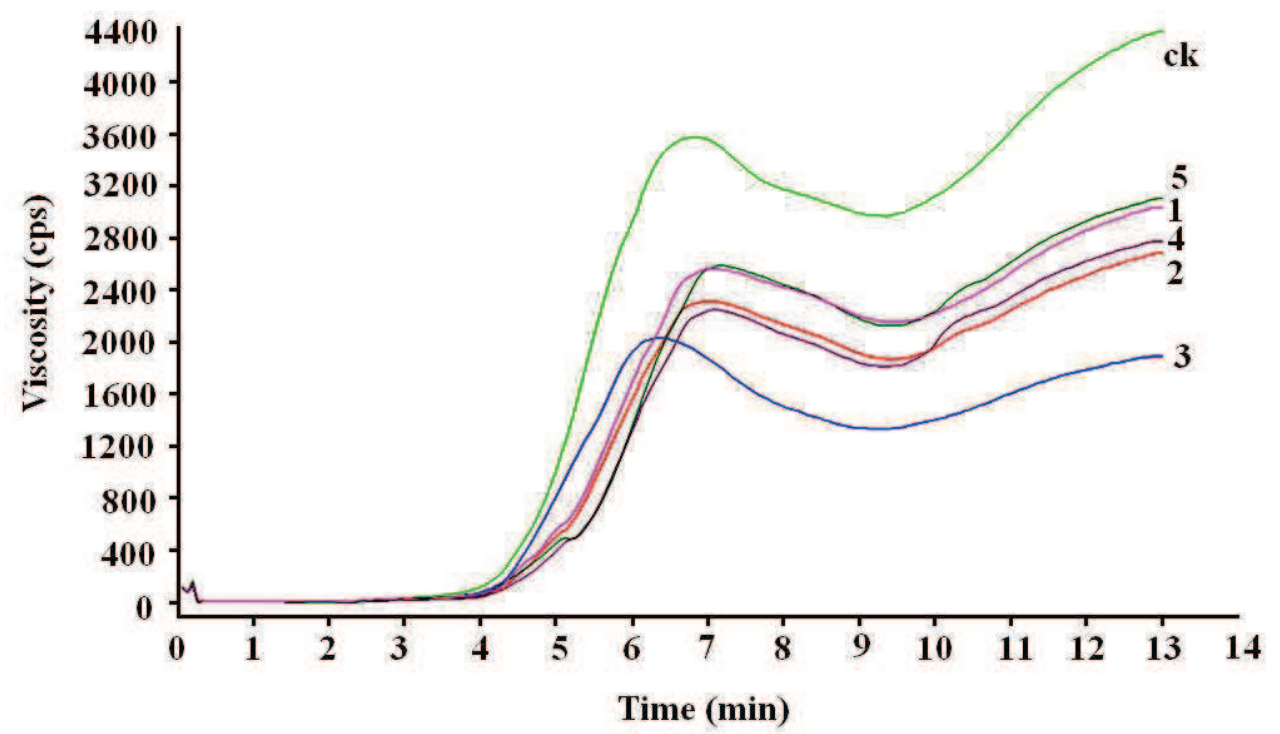

Fig 1: Viscosity profiles of wheat starches modified with varying levels of sucrose esters 
Key: ck $=$ Control; $1=0.10 \%$ sucrose esters; $2=0.20 \%$ sucrose esters; $3=0.30 \%$ sucrose esters; $4,0.40 \%$ sucrose esters; $5,0.50 \%$ sucrose esters

Table 2: DSC thermograms of wheat starch modified with sucrose ester

\begin{tabular}{lcccc}
\hline $\begin{array}{l}\text { Content of sucrose } \\
\text { ester }(\%)\end{array}$ & To $\left({ }^{\circ} \mathrm{C}\right)$ & $\mathbf{T p}\left({ }^{\circ} \mathbf{C}\right)$ & Tc $\left({ }^{\circ} \mathbf{C}\right)$ & $\Delta \mathbf{H}(\mathbf{J} / \mathbf{g})$ \\
\hline ck & 58.70 & 64.16 & $87.65^{*}$ & 3.979 \\
0.1 & 59.80 & 65.34 & 82.65 & 3.744 \\
0.2 & 62.04 & 66.55 & 82.52 & 3.534 \\
0.3 & 64.06 & 67.57 & 82.62 & 3.022 \\
0.4 & 63.65 & 65.82 & 81.82 & 2.629 \\
0.5 & 63.41 & 65.58 & 82.83 & 2.084 \\
\hline
\end{tabular}

* Significant at $p<0.05$

\section{Blue value}

Fig.2. showed the Blue value of wheat starches with different addition of sucrose esters,. compared with the control, the blue value of all the samples treated by sucrose esters decreased and the lowest BV (0.378) appeared in the sample with $0.3 \%$ sucrose esters. The results indicated that sucrose esters might have interferred with the iodine binding behavior of wheat starch.

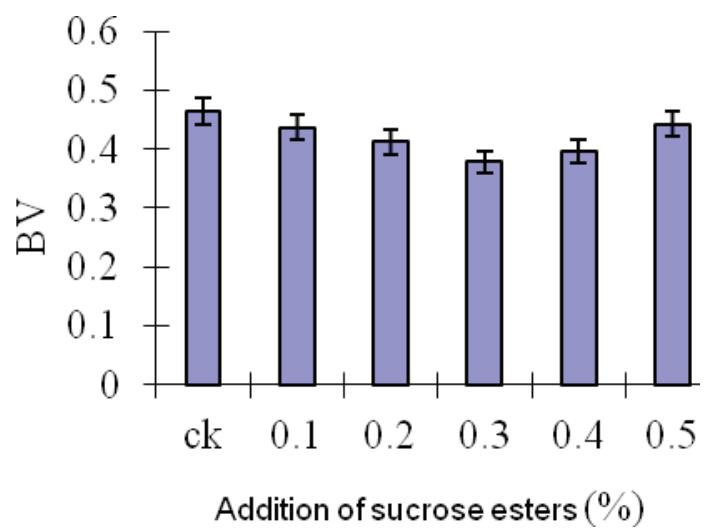

Fig 2: Blue value of wheat starches with varying levels of sucrose esters

\section{Retrogradation volume}

Fig. 3 shows the retrogradation volume of wheat starches with varying contents of sucrose ester. The starch sample with $0.3 \%$ sucrose ester had lowest supernatant volume $(76.6 \mathrm{~mL})$. The greater the supernatant volume, the stronger is retrogradation and the faster the starch ages. On the other hand, when the supernatant volume was smaller, retrogradation was weaker and the starch aged more slowly.

\section{Dissolution rate}

Fig.4 showed the effect of different addition of sucrose esters on dissolution rate of wheat starch. Dissolution rate of all the samples with sucrose esters decreased compared with the control. From Fig 4, the lowest dissolution rate $(0.056 \mathrm{~g})$ of starch was obtained by adding $0.4 \%$ sucrose esters. The starches with $0.30 \%$ sucrose esters had lower dissolution rate $(0.063 \mathrm{~g})$.

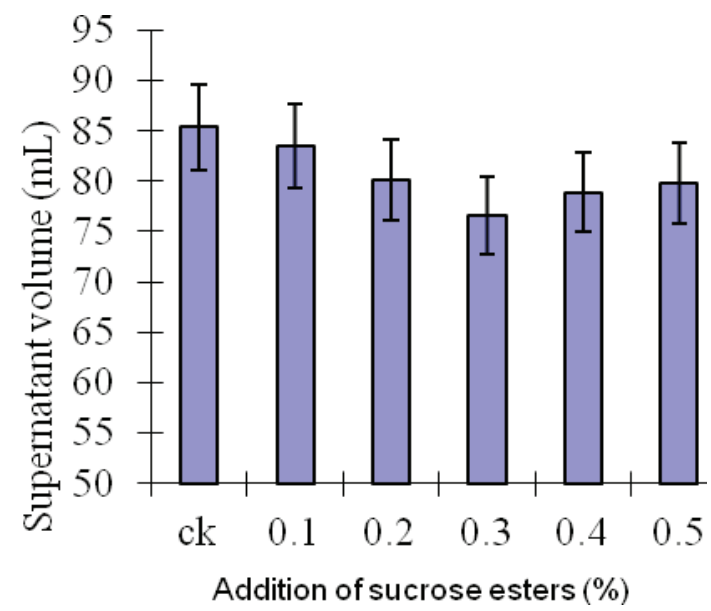

Fig 3: Retrogradation volume of wheat starch modified with various sucrose esters

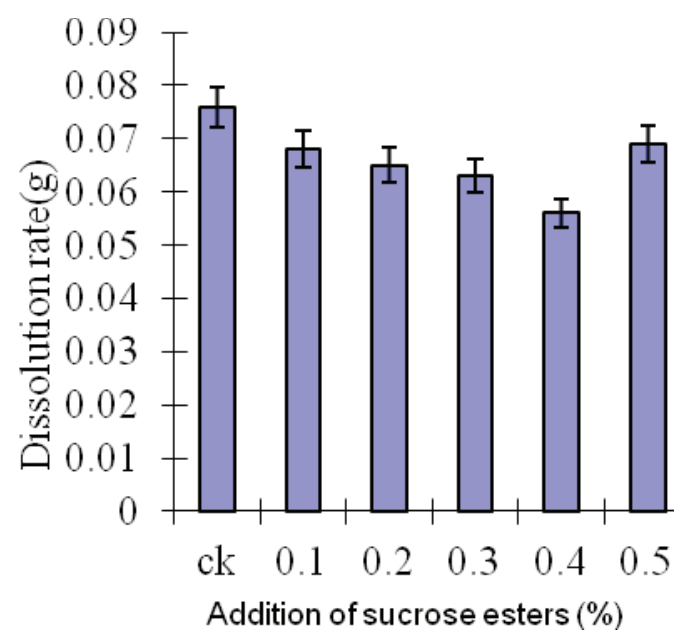

Fig 4: Dissolution rate of wheat starch nodified with sucrose ester

Trop J Pharm Res, October 2013;12 (5): 688 


\section{Thermal properties}

Table 2 illustrates the DSC thermograms of wheat starch with different addition of sucrose esters. For control samples, starting temperature $58.7^{\circ} \mathrm{C}$, termination temperature of $87.65^{\circ} \mathrm{C}$, the temperature span a range of $28.95{ }^{\circ} \mathrm{C}$, heat enthalpy $3.979(\mathrm{~J} / \mathrm{g})$. Sucrose esters could increase the gelatinization onset temperature (To) and peak temperature (Tp), but decrease the conclusion temperature (Tc) and enthalpy

change $(\Delta H)$. Furthermore, the temperature span

a range also decreased in all samples with different addition of sucrose esters.

\section{Scanning electron microscopy}

Wheat starch granules showed bimodal size distributions (Fig.5), The large starch granules displayed a disk shape with diameters 10-35 $\mu \mathrm{m}$, while the small starch granules displayed a spherical shape with diameters of about 2-9 $\mu \mathrm{m}$. The starch granules treated with $0.3 \%$ sucrose esters did not show any apparent morphological change.

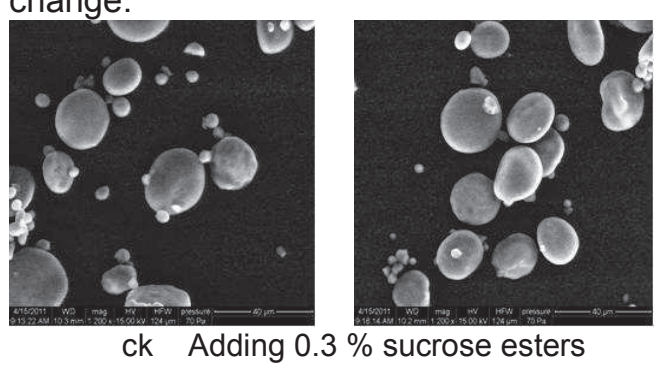

Fig 5: Scanning electron micrographs of starch granules

\section{Fourier transform infrared spectroscopy}

Fig. 6 shows FTIR spectra of the samples in the $4,000-500 \mathrm{~cm}^{-1}$ region. All the starch granules exhibited a similar pattern and showed 13 peaks in the $4,000-500 \mathrm{~cm}^{-1}$ region. The spectrum of starch was characterized by seven main modes, with maximum absorbance peaks near 3,500, $3,000,1,600,1,400,1,000,800$ and $500 \mathrm{~cm}^{-1}$ [18]. The band absorbance in starch have been assigned and matched with the vibrational modes of the chemical bonds and the structures of starch molecules by many researchers.

\section{DISCUSSION}

Sucrose esters are non-toxic, biodegradable, non-ionic surfactants. They have a wide range of hydrophilic-lipophilic balance values (1-16) and are usually applied as surfactants, or as solubility or penetration enhancers. Hence, sucrose esters can be applied in many areas of pharmaceutical technology in the case of liquid, plastic, semisolid and solid dosage forms as emulsifiers, solubilising agents, lubricants, penetrating enhancers, and pore forming agents [19]. Szüts et al studied the dissolution process and revealed that the gelling of the sucrose esters was temperature and concentration dependent and the stronger gel structure had a significant effect on the drug release[20]. They are also applied in cosmetical preparations [21] and food additives [22].
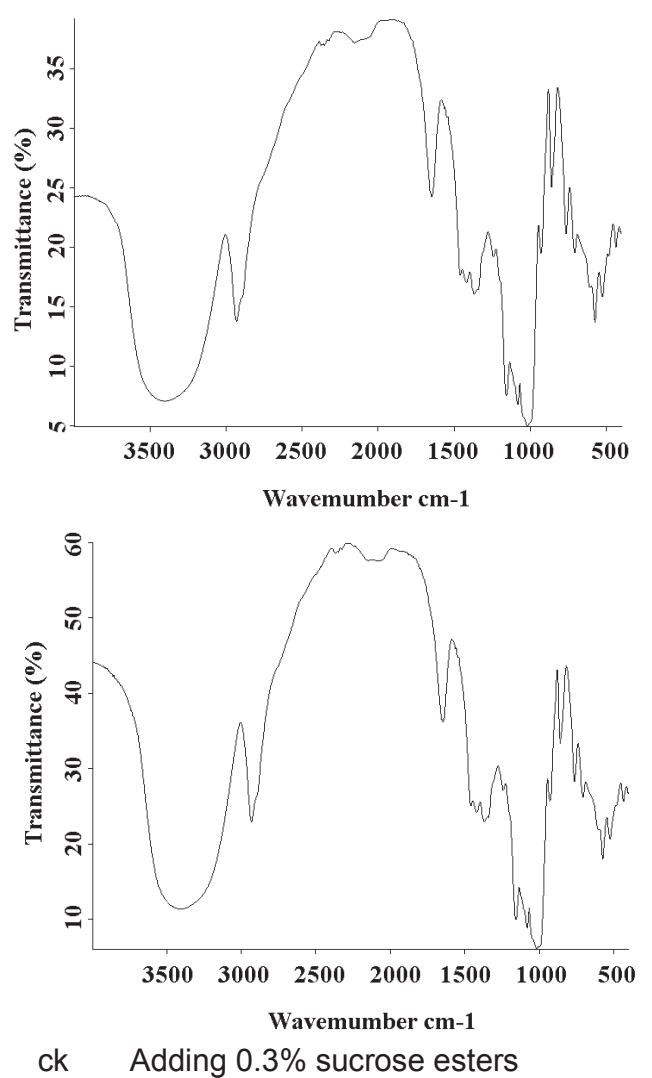

Fig 6: Infrared spectra of starch granules

In the present study, sucrose esters were used to improve some properties of wheat starch. As far as we know, studies on the modification of wheat starch by sucrose esters have previously not been reported. To some extent, the application of wheat starch was limited because of its properties.

RVA parameters indicate that sucrose esters decreases the peak, trough, final, setback viscosities. And blue value, supernatant volume, and dissolution rate of wheat starch were also decreased after adding into sucrose esters. This suggests that sucrose esters and starch granules combined into emulsifier-starch composite through the interaction between hydrophilic 
groups forming hydrogen bonds. Sucrose esters might also have penetrated the inside of the helical structure of amylose through the hydrophobic bond and combined into supramolecular, reducing the number of the hollow helical structure of amylase [19].

Since sucrose esters penetrated into the helical structure of amylose and combined at a supramolecular level through hydrophobic bond, amylose was fixed in the starch granules. As a result, the dissolution rate of starch moved freely around and the water decreased. On the other hand, SEM and IR data indicate that there was no difference between the modified wheat starches and control, which suggests that there was no significant effect of sucrose esters on the structure of wheat starch.

\section{CONCLUSION}

The microscopic structure of wheat starch modified by sucrose esters does not change substantially, although other physical and chemical properties such as lower peak, trough, final, setback viscosities, blue value, supernatant volume and dissolution rate vary. Thus, wheat starch modified by sucrose esters may be suitable for use in tablet as fillers and adhesives. Furthermore, unlike some other chemically modified starches, the starch modified with sucrose esters has a high safety profile since sucrose esters themselves are food additives. Thus, these modified starches have good application prospects in the pharmaceutical industry.

\section{ACKNOWLEDGEMENT}

This work was financially supported by the Science and Technology Plan and the Education Department of Henan Province (ref nos. 132102110032, 2010A550005 and 2010GGJS141)

\section{REFERENCES}

1. Jane AZ. Characterization and modeling of the $A$ - and $B$-granule starches of wheat, triticale, and barley. Carbohyd Polym 2007; 67(1): 46-55.

2. Liu Q, Gu Z, Donner E, Tetlow I, Emes M. Investigation of digestibility in vitro and physicochemical properties of A-and B-type starch from soft and hard wheat flour. Cereal Chem 2007; 84(1): 1521.

3. Shinde SV, Nelson JE, Huber KC. Soft wheat starch pasting behaviour in relation to $A$ - and B-type granule content and composition. Cereal Chem 2003; 80(1): 91-98.

4. Vermeylen $R$, Goderis B, Reynaers $H$, Delcour JA. Gelatinization related structural aspects of small and large wheat starch granules. Carbohyd Polym 2005; 62: 170-181
5. Salman H, Blazek J, Lopez-Rubio A, Gilbert EP, Hanley $T$, Copeland L. Structure-function relationships in $A$ and $B$ granules from wheat starches of similar amylose content. Carbohyd Polym 2009; 75: 420-427

6. Ao Z, Jane J-l. Characterization and modeling of the Aand B-granule starches of wheat, triticale, and barley. Carbohyd Polym 2007; 67: 46-55

7. Kim H-S, Huber KC. Channels within soft wheat starch A- and B-type granules. J Cereal Sci 2008; 48: 159-172.

8. Hung PV, Morita N. Physicochemical properties of hydroxypropylated and cross-linked starches from A-type and B-type wheat starch granules. Carbohyd Polym 2005; 59 : 239-246

9. Pilli TD, Carbone BF, Fiore AG, Severini C. Effect of some emulsifiers on the structure of extrudates with high content of fat. J Food Eng 2007; 79: 1351-1358.

10. Wijnans G, Baal H, Vianen G. Sucrose esters of fatty acids. Versatile emulsifiers covering a broad HLB-range. International Food Ingredients 1993; 6: 27-30.

11. Copeland L, Blazek J, Salman H, Tang MC. Form and functionality of starch. Food Hydrocolloid 2009; 23: 1527-1534.

12. Blazek J, Copeland L. Effect of monopalmitin on pasting properties of wheat starches with varying amylose content. Carbohyd Polym 2009; 78: 131-136.

13. Tufvesson F, Wahlgren M, Eliasson, A-C. Formation of amylose-lipid complexes and effects of temperature treatment. Part 1 Monoglycerides. Starch/Stärke 2003; 55: 61-71.

14. Zabar S, Lesmes U, Katz I, Shimoni E, Bianco-Peled $H$. Studying different dimensions of amyloseelong chain fatty acid complexes: molecular, nano and micro level characteristics. Food Hydrocolloid 2009; 23: 1918-1925.

15. Kasemsuwan $T$, Jane J, Schnable $P$, Stinard $P$, Robertson D. Characterization of the dominant mutant amylose-extender (Ael-5180) maize starch. Cereal Chem 1995; 71: 457-464

16. Gomand SV, Verwimp $T$, Goesaert H, Delcour JA. Structural and physicochemical characterisation of rye starch. Carbohyd Res 2011; 346: 27272735.

17. Koksel H, Masatcioglu T, Kahraman K, Ozturk S, Basman A. Improving effect of lyophilization on functional properties of resistant starch preparations formed by acid hydrolysis and heat treatment. J Cereal Sci 2008; 47: 275-282.

18. Sitohy MZ, Labib SM, El-Saadany SS, Ramadan MF. Optimizing the conditions for starch dry phosphorylation with sodium mono- and dihydrogen orthophosphate under heat and vacuum. Starch/Staerke 2000; 52: 95-100.

19. Thevenin MA, Grossiord JL, Poelman MC. Sucrose esters cosurfactant microemulsion systems for transdermal delivery: assessment of bicontinuous structures. Int J Pharm 1996; 137: 177-186.

20. Szüts A, Budai-Szücs M, Erős I, Otomo N, SzabóRévész $P$. Study of gel-forming properties of sucrose esters for thermosensitive drug delivery systems. Int J Pharmaceut 2010; 383: 132-137.

21. Ahsan F, Arnold JJ, Dennis EM, Pillion J. Sucrose cocoate, a component of cosmetic preparations, enhances nasal and ocular peptide absorption. Int J Pharm 2003; 251: 195-203.

22. Husband FA, Sarney DB, Barnard MJ, Wilde PJ. Comparison of foaming and interfacial properties of pure sucrose monolaurates, dilaurate and commercial preparations. Food Hydrocolloid 1998; 12: 237-244.

Trop J Pharm Res, October 2013;12 (5): 690 